\title{
The Amount of Immature Glial Cells in Organotypic Brain Slices Determines the Susceptibility to Murine Cytomegalovirus Infection
}

\author{
Hideya Kawasaki, Isao Kosugi, Yoshifumi Arai, and Yoshihiro Tsutsui \\ Second Department of Pathology, Hamamatsu University School of Medicine, Hamamatsu, Japan
}

SUMMARY: Cytomegalovirus (CMV) is the most common infectious cause of congenital anomalies of the brain and also causes brain damage in immunocompromised individuals. We investigated the effects of murine cytomegalovirus (MCMV) infection on the developing mouse brain in terms of susceptible cells and age-related resistance to MCMV in brain slice cultures. Brain slices from BALB/c mice at different developmental stages were infected with recombinant MCMV in which the lac $Z$ gene was inserted into a late gene. The subventricular zone and cortical marginal region were the sites most susceptible to MCMV infection, and the susceptibility declined with the development of the brain. Immunohistochemical staining showed that the virus-susceptible cells were positive for GFAP, nestin, and Musashi-1, and that most of the infected cells were positive for the proliferative cell nuclear antigen and labeled with bromodeoxyuridine. These results suggest that the susceptible cells in the subventricular zone are immature glial cells, including neural progenitor cells. Immature glial cells proliferated when the brain slices were cultured for a prolonged time and furthermore, they showed themselves to be susceptible to virus infection even under serum-free conditions. These results suggest that the amount of immature glial cells, which include neural progenitor cells, in the developing brain or in the damaged brain with neural proliferation may be closely associated with the susceptibility of the brain to CMV infection in humans. (Lab Invest 2002, 82:1347-1358).

C ytomegalovirus (CMV) is the most significant infectious cause of congenital anomalies of the central nervous system (CNS) caused by intrauterine infection in humans (Ho, 1991; Weller, 1971), with an average incidence of $1 \%$ of all live births (Demmler, 1991; Stagno et al, 1986). It is estimated that approximately $5 \%$ to $10 \%$ of infected infants have generalized cytomegalic inclusion disease at birth, with symptoms such as microcephaly, perivascular calcification, and microphthalmia (Bale, 1984; Becroft, 1981; Cinque et al, 1997). Another $10 \%$ of infected infants have subclinical congenital infection, and will subsequently suffer from brain disorders, including mental retardation, sensorineural hearing loss, visual disorders, seizures, and epilepsy (Conboy et al, 1986; Pass et al, 1980). In adults, infection with human CMV (HCMV) is usually asymptomatic in immunocompetent hosts, but the virus causes severe or fatal disease in immunocompromised patients (Britt and Alford, 1996). $\mathrm{CMV}$ has become the most frequent opportunistic cerebral infection in acquired immunodeficiency syndrome (AIDS), in which it results in CMV encephalitis/ encephalopathy such as ventriculoencephalitis (Morg-

DOI: 10.1097/01.LAB.0000032376.58688.D4

Received May 9, 2002.

This work has been supported in part by a grant (no. 10670284) from the Ministry of Education, Science, and Culture, Japan.

Address reprint requests to: Dr. Yoshihiro Tsutsui, Second Department of Pathology, Hamamatsu University School of Medicine, 1-20-1 Handayama,

Hamamatsu 431-3192,Japan.E-mail:ytsutsui@hama-med.ac.jp ello et al, 1987; Setinek et al, 1995; Wiley and Nelson, 1988).

Because studies of human subjects have obvious limitations, we have developed model systems for brain abnormalities induced by infection of mouse embryos with murine CMV (MCMV) (Li and Tsutsui, 2000; Tsutsui, 1995; Tsutsui et al, 1993). The susceptibility of mice to MCMV infection in vivo has been reported to diminish with age (Hayashi et al, 1985; Tsutsui, 1995). The resistance is thought to be due to development of host defense mechanisms such as those mediated by natural killer (NK) cells (Brutkiewicz and Welsh, 1995) and macrophages (Booss et al, 1989). It is rather difficult to standardize experimental conditions for in vivo analysis of brain susceptibility to virus infection. However, the susceptibility of cells to CMV infection in vivo is markedly different from that in vitro (Britt and Alford, 1996). It should be noted that analysis of isolated cultured cells may not reflect the phenomena that occur in vivo in terms of in situ cellular interactions and defense responses.

Brain slice cultures provide a useful experimental system because they preserve the three-dimensional architecture and local environment of brain cells, including neurons, glial cells, microglias, and other immune cells, to a greater extent than dissociated cell cultures. In addition, they permit experimental manipulations and observations to be performed (Lo et al, 1994). We previously developed procedures for infection of the subventricular zone (SVZ) of brain slice cultures with MCMV, and showed that infected neurons migrate to the cortex in a way similar to that seen 
in in vivo infection (Shinmura et al, 1999). We also showed age-related susceptibility of brain slice cultures to MCMV in preliminary experiments (Shinmura et al, 1999).

In the present study, we analyzed the age-related susceptibility to MCMV infection in brain slice cultures from the viewpoint of brain architecture and cell differentiation, and found that the amount of immature glial cells, including neural progenitor cells, in the SVZ may be the primary factor in the susceptibility.

\section{Results}

\section{Age-Related Susceptibility to MCMV Infection in Brain Slice Cultures}

Brain slice cultures from 0-day-old, 7-day-old, 14day-old, and 21-day-old BALB/c mice were infected with recombinant $\mathrm{MCMV}(\mathrm{RM} 461)\left(5 \times 10^{6}\right.$ plaque forming units (PFU)/ml) by whole immersion, and cultured for 3 days (Fig. 1A, a, c, e, and g) or 5 days (Fig. $1 A, b, d, f$, and $h)$. The brain slices were fixed and stained with $\mathrm{X}$-Gal (5-bromo-4-chloro-3-indolyl- $\beta$ galactoside), and $\beta$-Gal ( $\beta$-galactosidase) expression was visualized as blue spots. Staining of cells by X-Gal indicates expression of the late gene of MCMV in these cells. In the slices from 0-day-old mice, virusinfected cells were scattered throughout the slices (Fig. 1A, a and b). In the slices from 7-day-old mice, virus-infected cells tended to be localized in the marginal regions of the cortex and around the ventricles (Fig. 1A, c and d). In the slices from 14-day-old and 21-day-old mice, this tendency of the localization of the virus-infected cells was conspicuous, and the localization tended to be confined more to the periventricular regions (Fig. 1A, e to h). The number of infected cells stained with X-Gal decreased with increasing age of the mice.

The virus-infected area was quantitatively estimated by scanning the X-Gal-stained areas using PhotoShop image analysis. The ratio of the $\mathrm{X}$-Gal-stained area to the whole-slice area was the highest in the slices from 0 -day-old mice and became progressively smaller in the slices from 7-, 14-, and 21-day-old mice (Fig. 1B). There was no significant difference between the ratio in the brain slices from BALB/c mice and C57BL/6 mice (Fig. 1B).

Because the cells in the SVZ seemed to be susceptible to MCMV infection, virus-containing solution was injected into portions of the SVZ, cerebral cortex, and striatum in brain slices from 21-day-old mice using a microcapillary pipette with a micromanipulator (Fig. $1 \mathrm{C}, \mathrm{a})$. Viral infection detected by $\mathrm{X}-\mathrm{Gal}$ staining was observed only in the SVZ portion 5 days after injection (Fig. 1C, b).

\section{Immature Glial Cells, Which Include Neural Stem Cells, in the SVZ Susceptible to MCMV Infection}

Brain slices from 7-day-old mice were stained with $\mathrm{X}-\mathrm{Gal} 3$ days after infection and then dehydrated, embedded in paraffin, and thin sectioned. Immunohis-
A
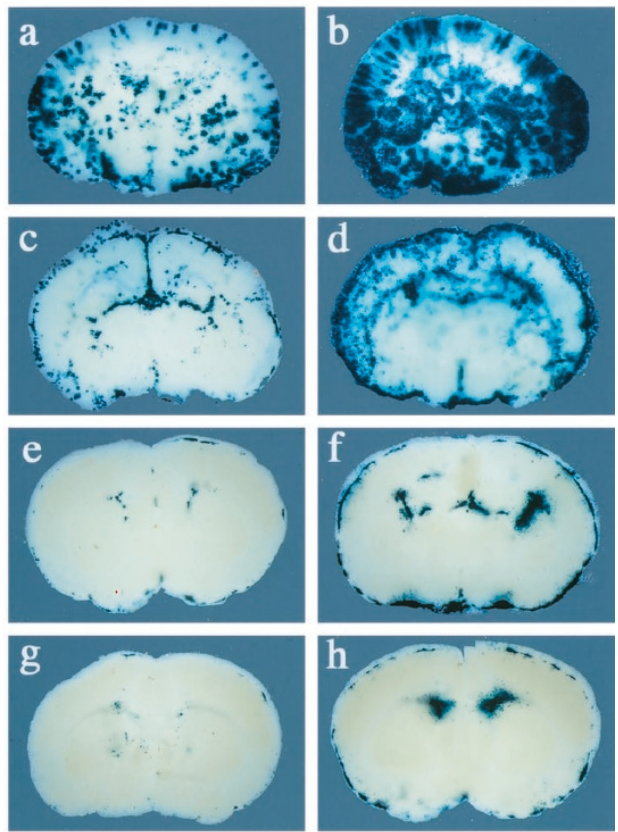

B

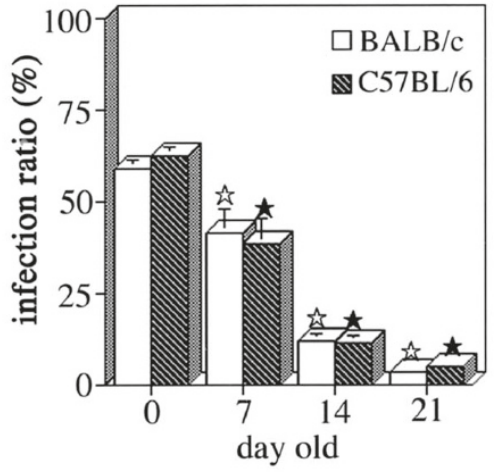

C
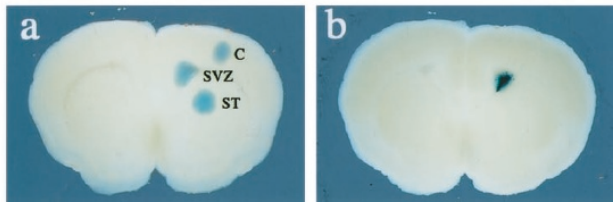

Figure 1.

A, Age-dependent changes of $\beta$-galactosidase ( $\beta$-Gal) expression in the brain slice cultures from mice of different ages after murine cytomegalovirus (MCMV) infection. The brain slice cultures from 0-day-old ( $a$ and $b$ ), 7-day-old (c and d), 14-day-old (e and f), and 21-day-old ( $g$ and $h$ ) BALB/c mice were infected with recombinant MCMV (RM461) $\left(5 \times 10^{6} \mathrm{PFU} / \mathrm{ml}\right)$ by whole immersion, and cultured for 3 days ( $a, c, e$, and $g$ ) or 5 days (b, $d, f$, and $h$ ). In the 0-day-old slices (a and b), virus-infected cells are scattered throughout the slices. In the 7-day-old slices ( $c$ and d), virus-infected cells tend to be localized in the subventricular zone (SVZ) and the marginal regions of the cortex, and thereafter tend to be confined more to the ventricular wall than the marginal regions. B, Quantitative analysis of infection rates in brain slices after 5 days of infection by estimation of the X-Gal-stained area per whole brain slice area using Photoshop image software. The infection ratio was the highest in the 0-day-old slices and became progressively lower in 7-, 14-, and 21-day-old slices. There was no significant difference between the ratios in the brain slices from BALB/c mice and those from C57BL/6 mice. Data are expressed as the mean \pm SD of at least three independent experiments. $\star$ or is $p<0.05$ compared with 0-day-old slices. C, The SVZ is susceptible to MCMV infection after injection of virus. a, MCMV solution supplemented with fast green dye was injected into portions of the SVZ, cerebral cortex (C) or striatum (ST) using a microcapillary pipette. b. Only the injected SVZ portion expressed $\beta$-Gal 5 days after injection. 
tochemical staining demonstrated that the X-Galpositive cells (blue) around the ventricular walls expressed glial fibrillary acidic protein (GFAP) (Fig. 2A; brown), a primitive neuroectodermal marker, nestin (Lendahl et al, 1990) (Fig. 2B; brown), and a marker of CNS progenitor cells including neural stem cells, Musashi-1 (Kaneko et al, 2000) (Fig. 2C; brown). Representative double-stained cells are indicated by arrows.

The infected cells immunostained by the N2 antibody specific to MCMV immediate-early (IE) antigen 1 (Shinmura et al, 1997a; blue) were also double-stained with antibodies specific to GFAP (Fig. 2D), nestin (Fig. 2E), and Musashi-1 (Fig. 2F; brown), but not with antibody to MAP2 (microtubule-associated protein 2a and 2b) (Fig. 2G). To show that X-Gal-positive cells were actually infected, X-Gal-stained sections were immunostained with N2 antibody. Most of the X-Galpositive cells (blue) expressed MCMV IE antigen 1 (Fig. 2H; red).

Previous studies showed that vascular endothelial cells are frequently infected in tissues, including the brain, obtained from HCMV-infected patients (Sinzger et al, 1995; Söderberg-Nauclér and Nelson, 1999). Examination of the $\mathrm{X}$-Gal-positive cells around the SVZ revealed that they rarely expressed von Willebrand factor, a marker for vascular endothelial cells. A small fraction of the X-Gal-positive cells was doublestained for this endothelial cell marker (Fig. 2l). These data strongly support the conclusion that the majority of infected cells (X-Gal-positive cells) in the brain slices expressed immature glial cell markers. It has been reported that neural progenitor cells in the ventricular zone and SVZ are also positive for GFAP,
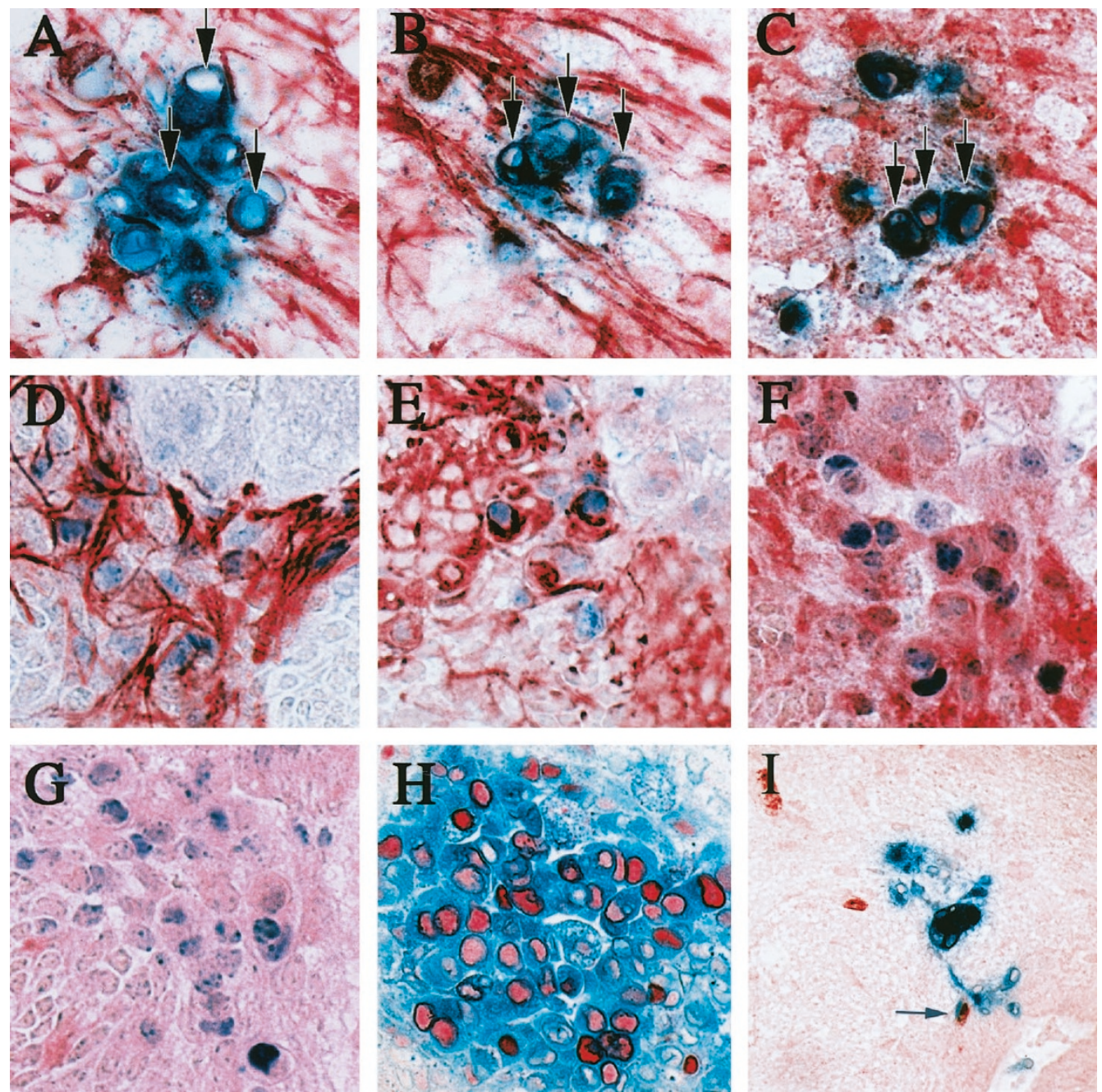

\section{Figure 2.}

Immunohistochemical analysis of MCMV-infected brain slices using antibodies specific to neural cell markers and MCMV antigen. Brain slice cultures from 7-day-old mice were infected with mutant MCMV (RM461) and stained with X-Gal after 3 days of infection. X-Gal-positive cells (blue) around the ventricular walls were double-stained with antibodies to GFAP (A), nestin (B), and Musashi-1 (C) (brown). Double-stained cells show black in the cytoplasm (arrows). Immunohistochemical double-staining was performed using N2 antibody to MCMV immediate-early (IE) antigen 1 (blue) and the antibodies to GFAP, nestin, or Musashi-1 (brown). The viral antigen-positive cells were stained with the antibodies to GFAP (D), nestin (E), and Musashi-1 (F), but not MAP2 (G). Most of the X-Gal-positive cells (blue) around the subventricular zone were double-stained with the N2 antibody (red) $(\mathrm{H})$. Most of the X-Gal-positive cells were not double-stained with antibody against an endothelial marker. Only a few were double-stained (arrow) (I). Original magnification, $\times 560$ (A to C), $\times 400$ (D to G), $\times 360(\mathrm{H}), \times 90$ (I). 
nestin, and Musashi-1, but not for MAP2 (Doetsch et al, 1999; Kaneko et al, 2000).

We made quantitative analyses of infected cells and cells stained for markers for immature neural cells or neural progenitor cells. We counted the cells immunostained with the antibodies to nestin and Musashi-1 in the coronal serial sections from 0-day-, 14-day-, and 21-day-old BALB/c mice (Fig. 3, B and C) and compared these numbers with the ratio of infected cell area per section (Fig. 3A). The ratio of infected cell area and the total number of neural immature/progenitor marker-expressing cells per section significantly decreased with increasing development (Fig. 3, A to C).

\section{Proliferation of MCMV-Susceptible Immature Glial Cells, Which Include Neural Progenitor Cells, in Brain Slices Cultured for a Prolonged Period}

Brain slice cultures from 21-day-old BALB/c mice were infected with mutant MCMV (RM461) soon after the slices were made, or after the slices were incubated for 7 or 14 days before virus infection. After infection, all of the slices were incubated for a further 3 days, fixed, and stained with X-Gal. The X-Galpositive area increased as the culture period before infection increased in the serum-containing medium (Fig. 4A, a, c, and e, and 4B). Because the X-Galpositive regions were mostly confined to the SVZ, it seemed that neural progenitor cells that were susceptible to MCMV infection might have proliferated during brain slice culturing. However, it is well known that synergistic factors present in serum cause microglia activation and astrocyte proliferation (Coltman and Ide, 1996; Colton et al, 1992). To prevent these effects, we cultured the slices in serum-free medium, thus mimicking the serum-free environment found in the parenchyma of the CNS. The X-Gal-positive area also increased to some degree as the culture period before infection was increased in the serum-free medium (Fig. 4A, b, d, and f, and 4B). However, the number of virus-infected cells stained with $X$-Gal was significantly higher in the brain slices cultured in serum-containing medium than in those cultured in serum-free medium (Fig. 4B).
We confirmed that the periventricular cells proliferated during the culture period, and that these cells were stained with antibodies to GFAP (Fig. 5A, a to d), nestin (Fig. 5A, e to h), and Musashi-1 (Fig. 5A, i to I). Most of the proliferating cells were stained with antiproliferative cell nuclear antigen (PCNA) antibody (Fig. $5 \mathrm{~A}, \mathrm{~m}$ and $\mathrm{n}$ ) and specifically labeled with bromodeoxyuridine (BrdU) after incubation for 14 days in the presence of BrdU (Fig. 5A, o and p). The proliferating periventricular cells after incubation for 2 weeks were specifically susceptible to virus infection (Fig. 5A, c, d, $\mathrm{g}, \mathrm{h}, \mathrm{k}, \mathrm{l}$, and $\mathrm{m}$ to $\mathrm{p}$ ).

To compare the amount of glial cells with immature phenotype in the brain sections between brain slices cultured in serum-free medium and those cultured in serum-containing medium, we counted the cells immunostained with antibodies to GFAP, nestin, and Musashi-1 in 0-day-cultures and 14-day-cultures before infection. The total area of infected cells and the number of cells expressing neural immature/progenitor markers (nestin and Musashi-1) per section showed a significant increase in the brain slices cultured for 2 weeks in comparison with the freshly prepared brain slices under both culture conditions (Fig. 5B, a to c). However, the number of cells stained for neural immature/progenitor cell markers was significantly lower in slices cultured in serum-free medium than in those cultured in serum-containing medium (Fig. 5B, a to c), regardless of the culture period.

\section{Expression of the MCMV Immediate-Early Gene Promoter-lacZ in Brain Slices Injected Using a Gene Gun}

The expression of the CMV IE genes is dependent on cellular transcription factors that bind to the DNA sequence of the CMV IE enhancer/promoter (Ghazal and Nelson, 1993; Nelson et al, 1990). The MCMV IE promoter-lacZ DNA coated on gold microcarriers was released by a shock of helium into brain slices in a vacuum chamber. Gene-transferred brain slices were cultured for 48 hours, fixed, and stained with X-Gal. Expression of the gene was observed as dots mainly in the periventricular walls (SVZ) (Fig. 6A, a and b). The amount of expression in brain slices from 21-day-old
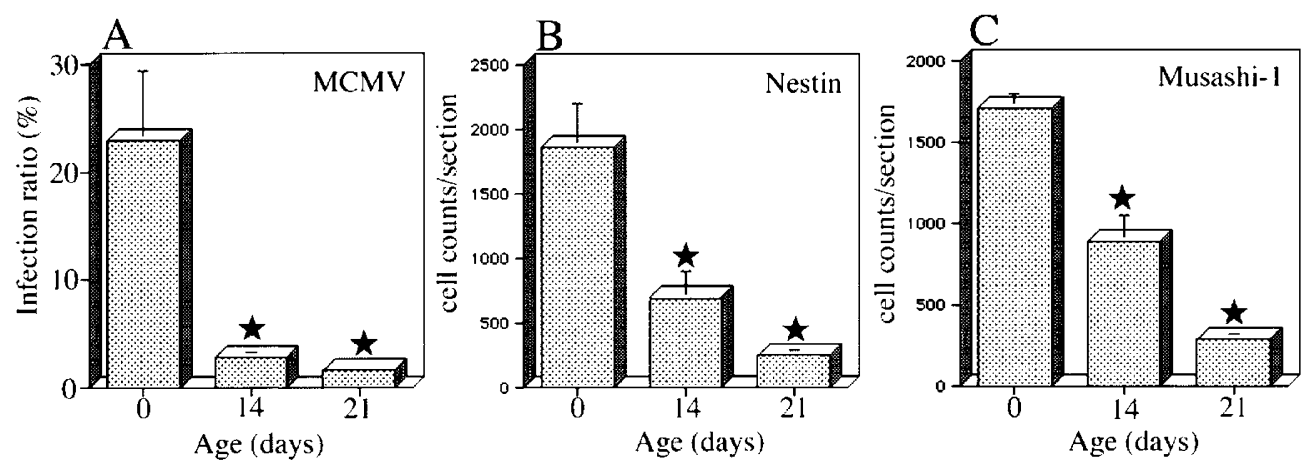

Figure 3.

Comparison of the infection ratio $(A)$ and the numbers of cells immunostained with the antibodies specific to nestin (B) and Musashi-1 (C) between the coronal serial sections from 0-, 14-, and 21-day-old BALB/c mice. The total numbers of infected and neural marker-expressing cells per section significantly decreased with development. Data are expressed as the mean $\pm \mathrm{SD}$ of at least three independent experiments. $\star p<0.01$ versus 0 -day-old mice. 
A
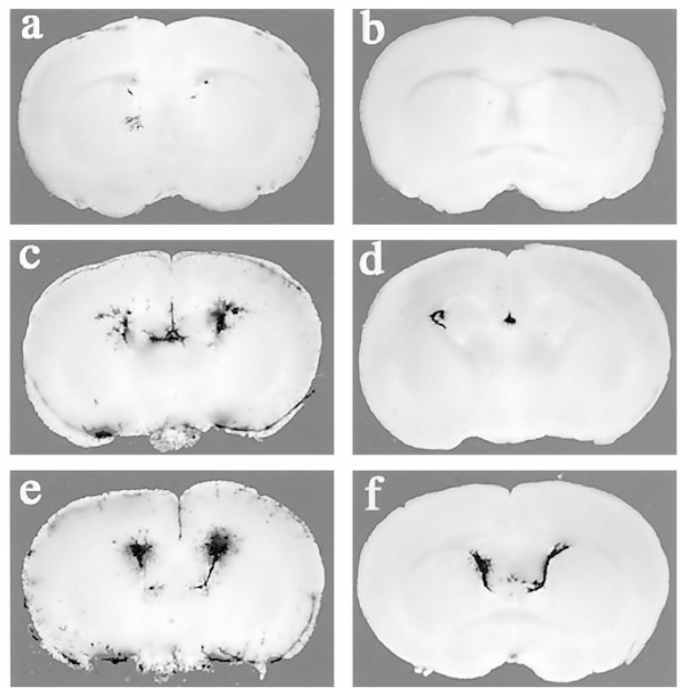

B

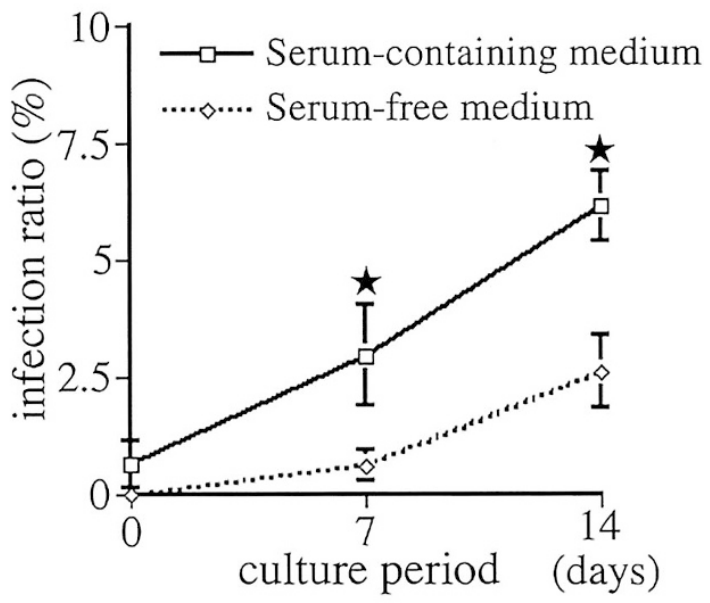

Figure 4.

A, Increase of infected cells by prolonged period of culturing before MCMV infection. Brain slices from 21-day-old BALB/c mice (a to f) were cultured for 0 days (a and $b$ ), 7 days ( $c$ and d), or 14 days (e and f) before infection with mutant MCMV (RM461). The brain slices were cultured in serum-containing medium (a, $c$, and e) or serum-free medium (b, d, and f). The infected slices were incubated for 3 days, then fixed and stained with X-Gal. The number of X-Gal-positive cells increased when the culture period before infection was longer. The number of virus-infected cells stained with X-Gal was significantly higher in brain slices cultured in serum-containing medium than in those cultured in serum-free medium. B, Comparison of the susceptibility of brain slices cultured in serum-containing medium with those cultured in serum-free medium. Brain slices from 21-day-old mice were cultured for the indicated periods before infection as described in A. Infection ratios were calculated as described in Figure 1B. The infection ratios of brain slices cultured in serum-containing medium were significantly higher than those of brain slices cultured in serum-free medium. Data are expressed as the mean \pm SD of at least three independent experiments. $\star p<0.05$ compared with brain slices cultured in serum-free medium.

mice was markedly decreased (Fig. 6A, b). Quantitative analysis showed that the amount of expression was almost the same in the brain slices from 0-day-old mice as in the slices from 7-day-old mice, but was markedly decreased in the brain slices from 14- and 21-day-old mice (Fig. 6B). After slices were embedded in paraffin and sectioned, immunohistochemical analysis was performed using the same neural progenitor cell markers. The X-Gal-stained cells were doublestained with antibodies to GFAP, nestin, and Musashi-1, but not with antibody to MAP2 (data not shown). After the brain slices were cultured for 14 days in serum-containing medium, the IE gene was transferred into them using a gene gun. The total number of X-Gal-positive cells was increased significantly in the brain slices cultured for 14 days compared with the number in the 0-day-cultured slices (Fig. 6C).

\section{Discussion}

It has been reported that the susceptibility of mice to MCMV infection in vivo diminishes with age (Hayashi et al, 1985; Tsutsui et al, 1995). In a previous report, we showed that the susceptibility to MCMV infection decreased in brain slice cultures with development of the brain (Shinmura et al, 1999), and this was confirmed by van den Pol et al (2000). It has been reported that resistance to $\mathrm{MCMV}$ infection is due to the development of host defense mechanisms such as NK cells (Brutkiewicz and Welsh, 1995). The NK protection against MCMV infection is in part related to a defined resistance gene locus, Cmv-1, mapping to chromosome 6 in the NK complex region (Forbes et al, 1997; Scalzo et al, 1990). It was reported that C57BL/6 mice, which have the $\mathrm{Cmv}-1$ resistant allele, are less susceptible to MCMV infection than BALB/c mice, which do not have the allele (Scalzo et al, 1992). However, the susceptibility to MCMV infection of brain slice cultures from BALB/c mice was not different from that of slices from C57BL/6 mice. It is possible that immunologic defense mechanisms to MCMV infection work poorly in brain slice cultures.

In the present study, we showed that cells in the SVZ and the cortical marginal regions in brain cultures are most susceptible to MCMV infection. The number of susceptible cells diminished with age and the susceptible cells became restricted to the SVZ as brain development proceeded. The fact that cells of the SVZ are especially susceptible to MCMV was further confirmed by our finding that only cells in the SVZ injected with virus using a micromanipulator expressed $\beta$-Gal, whereas cells in the cortex and striatum did not. The SVZ consists mostly of undifferentiated neuroepithelial cells, which include neural stem cells and neural progenitor cells (Doetsch et al, 1999; Kaneko et al, 2000; Sakakibara et al, 1996). Virus-infected cells were double-stained with antibodies to stem cell markers such as nestin and Musashi-1 (Barres, 1999; Mckay, 1997) and also to GFAP (Alvarez-Buylla et al, 2001; Doetsch et al, 1999). However, these stem cell markers were reported to be expressed also in the neural progenitor cells and 
A
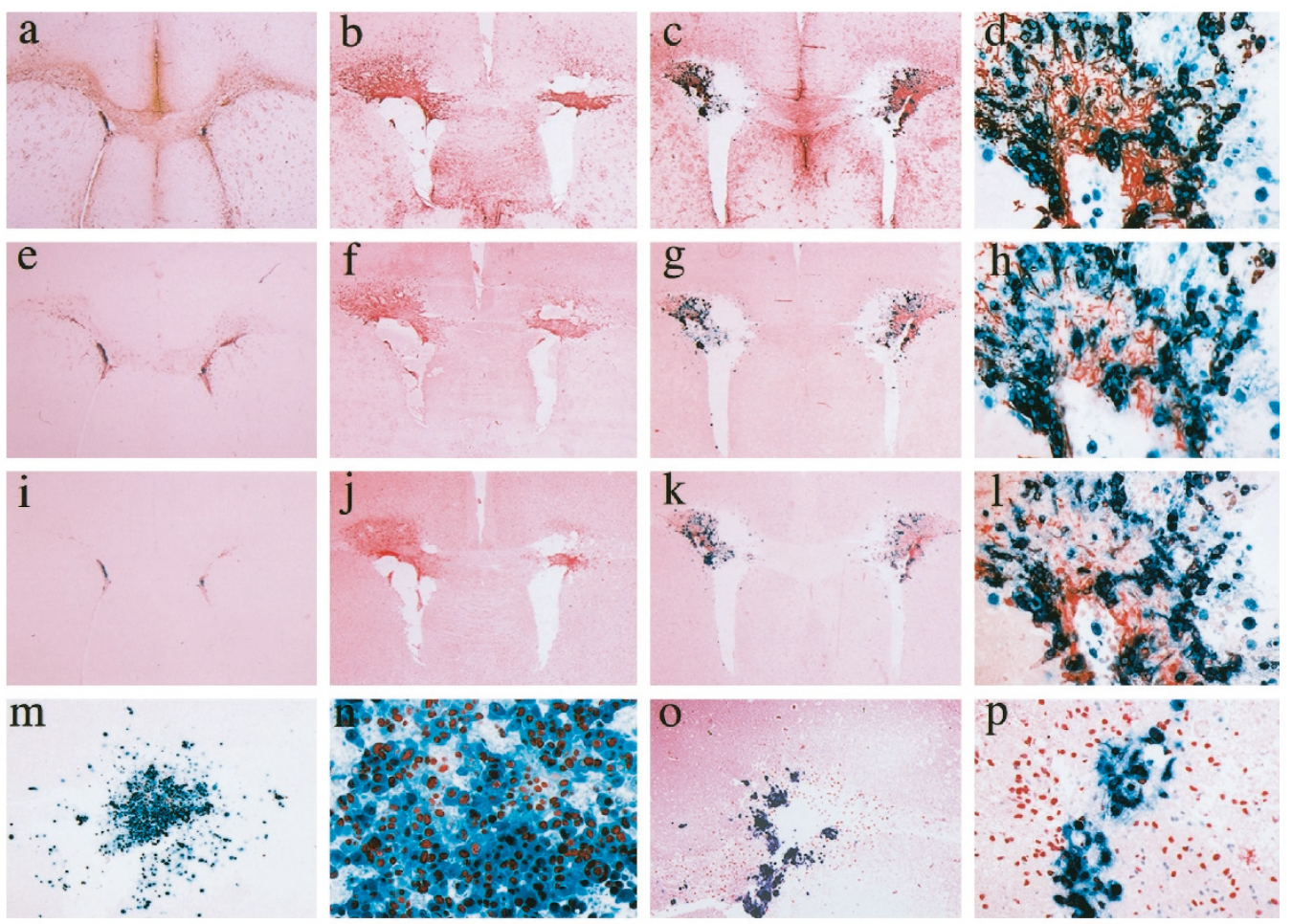

B
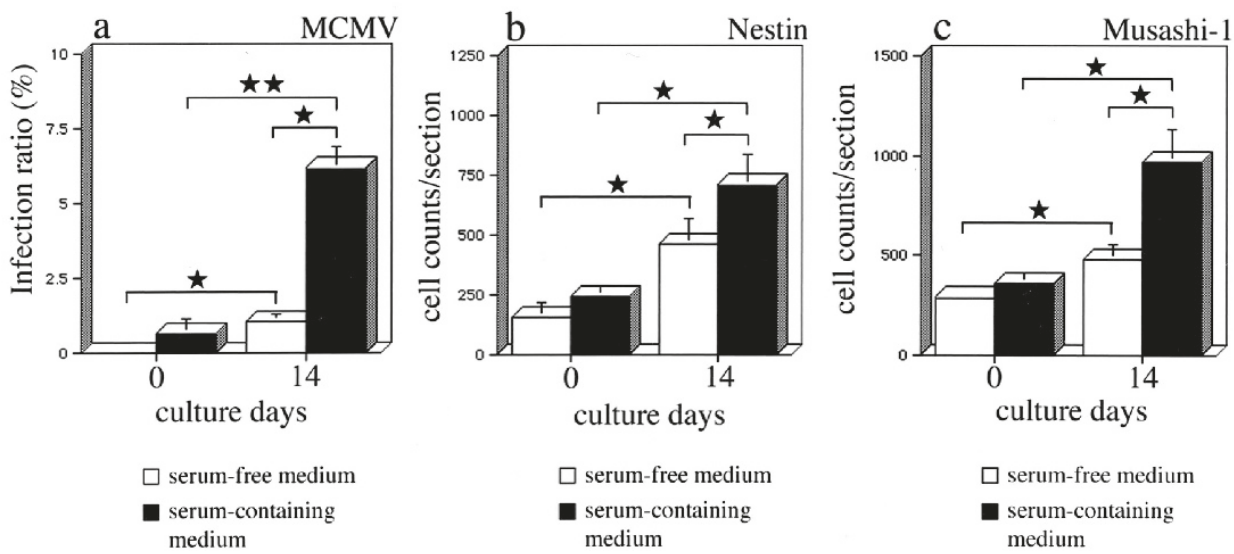

Figure 5.

A, Immunohistochemical staining of proliferating cells in SVZ of brain slices cultured for 14 days. Brain slices from 21-day-old BALB/c mice were cultured for 0 days (a, e, and i) or 14 days (c, d, g, h, k, l, and $m$ to p), infected with mutant MCMV (RM461) for 3 days and then stained with X-Gal. Some brain slices were not infected after 14 days of culturing ( $b, f$, and j). Additional immunohistochemical staining was performed with antibodies to GFAP (a, b, c, and d), nestin (e, $f, g$, and $h$ ), and Musashi-1 (i, j, k, and I). Most of the proliferating X-Gal-positive cells in the SVZ after incubation for 2 weeks were stained with PCNA antibody ( $m$ and $n$ ) and specifically labeled with BrdU when it was added to the medium for 14 days ( 0 and $p$ ). The proliferating periventricular cells after incubation for 2 weeks were positive for GFAP (c), nestin (g), and Musashi-1 (k) and susceptible to MCMV infection. Most of the infected cells were double-stained with the antibodies to GFAP (d), nestin (h), and Musashi-1 (I). Original magnification, $\times 10$ (a to c, e to g, and i to k), $\times 100$ (d, h, and I), $\times 30$ (m and o), $\times 150(n)$, and $\times 120(p)$. B, Comparison of infection ratios and numbers of neural progenitor cells in the brain sections of 0 -day-cultures versus 14-day-cultures. Brain slices from 21 -day-old mice were cultured for 0 or 14 days before infection. Infection ratios (a) and the number of cells immunostained for nestin (b) and Musashi-1 (c) were determined as described in Figure 3. The number of cells immunostained for neural immature/progenitor cell markers significantly increased in the brain sections of 14-day cultures under both serum-containing and serum-free culture conditions, but the number of cells stained for neural immature/progenitor cell markers was significantly lower in slices cultured in serum-free medium than in those cultured in serum-containing medium. Data are expressed as the mean \pm SD of at least three independent experiments. $\star p<0.05$ and $\star \star p<0.01$.

immature glial cells (Kaneko et al, 2000). Therefore, cells susceptible to MCMV infection in the SVZ were thought to be immature glial cells and neural progenitor cells, which include neural stem cells. In this present study, it was difficult to clearly differentiate among these three types of cells using these markers in the brain slices. In human and mouse CMV infection, CMV tends to preferentially infect the ventricular 
A
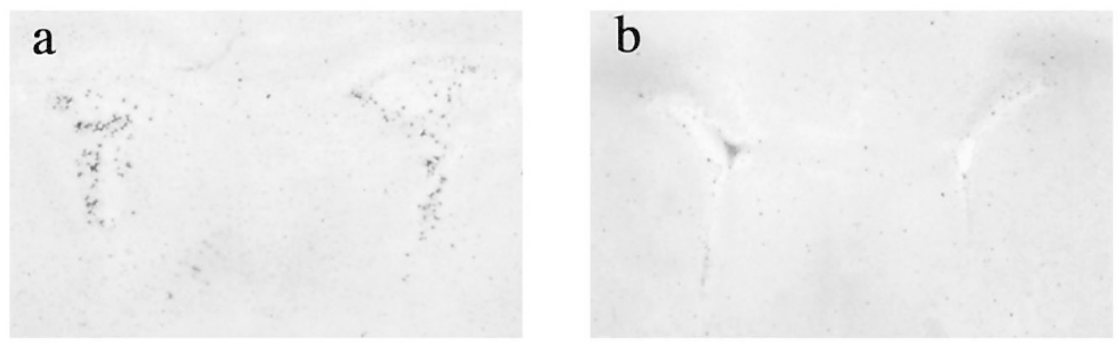

B
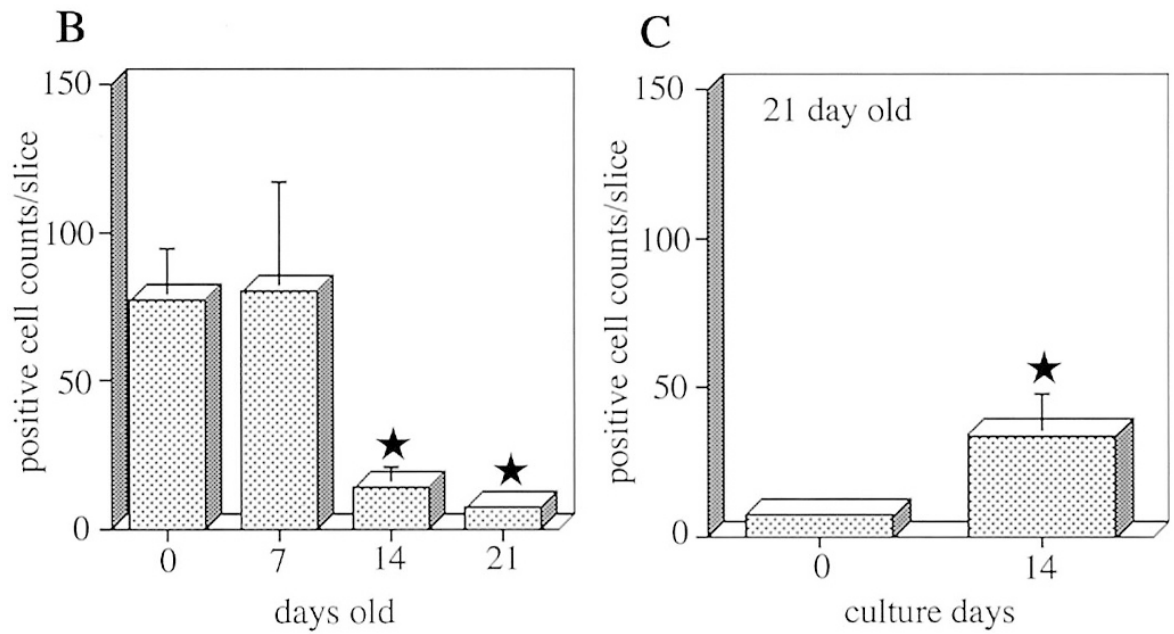

Figure 6.

A, Expression of the MCMV IE gene promoter-lacZ in brain slices injected using a gene gun. DNA-coated gold particles were injected into brain slices from 7-day-old (a) and 21-day old BALB/C (b) mice. X-Gal staining was performed after 48 hours of incubation. Expression of the gene was observed as dots mainly in the SVZ. The amount of expression in brain slices from 21-day-old mice was markedly decreased (b). B, Quantitative analysis of expression of the MCMV IE gene promoter-lacZ in brain slices injected using a gene gun. Positive expression was estimated as dots per slice in the brain slices from 0-, 7-, 14-, and 21-day-old mice. Quantitative analysis showed that the amount of expression was almost the same in the brain slices from 0-day-old mice as in the slices from 7-day-old mice, but was markedly decreased in the brain slices from 14- and 21-day-old mice. $\star p<0.05$ compared with slices from 0-day-old mice. C, Quantitative analysis of expression of the MCMV IE gene promoter-lacZ in the cultured brain slices injected using a gene gun. The total number of X-Gal-positive cells increased significantly after the brain slices were cultured. $\star p<0.05$ compared with 0 days of culture.

walls, including the ventricular zone and SVZ (Becroft, 1981; Kosugi et al, 2000; Li and Tsutsui, 2000; Perlman and Argyle, 1992; Shinmura et al, 1997a, 1997b; van den Pol et al, 2000).

In isolated cell cultures infected with MCMV, the kinetics of viral titers and viral antigen expression of neural stem cells were slower than those of mouse embryonic fibroblasts, which are known to be fully permissive for MCMV replication (Kosugi et al, 2000). Similarly, the rate of viral replication in glial cultures was significantly higher than that in neuronal cultures (van den Pol et al, 1999). Although the brain slice culture contains cells susceptible to MCMV infection, such as glial cells and endothelial cells, in addition to neural progenitor cells, the susceptibility to CMV tends to be confined to the SVZ and marginal area in the brain slice cultures. The brain slice culture system used in the present experiments represents a model of acute MCMV encephalitis in which immature glial cells were observed to be more permissive to $\mathrm{CMV}$ than neurons. It is possible that maintaining the threedimensional architecture is important for protecting cells of the cortex and white matter from viral infection.
Microcephaly and polymicrogyria are the most prominent brain abnormalities in congenital CMV infection (Becroft, 1981; Perlman and Argyle, 1992). The susceptibility of immature cells, including neural progenitor cells, in the SVZ to CMV infection may cause these brain abnormalities. Virus-infected cells migrated ventriculofugally from the SVZ to the cortical plates in human cases (Perlman and Argyle, 1992) and also in a mouse model (Shinmura et al, 1997a, 1997b). It is possible that CMV infection affects the proliferation of the progenitor cells in the SVZ, the neuronal migration toward the cortical plate, and the lamination of the cortex, as well as selective removal of the neuronal cells by apoptosis (Crino and Eberwine, 1997).

Interestingly, immature glial cells, including neural progenitor cells, proliferated in the SVZ and marginal area during the incubation of brain slices, and these cells were preferentially susceptible to MCMV infection. These proliferating cells seemed to contain neural stem/progenitor cells, because they were shown by immunostaining to express GFAP, nestin, and Musashi-1 (Doetsch et al, 1999; Kaneko et al, 2000; McKay, 1997) and proliferated even in serum-free 
medium. Furthermore, these cells were positive for PCNA and were also specifically labeled with BrdU, confirming that these cells are proliferating or regenerating (Haydar et al, 2000; Magavi et al, 2000). It has been reported that neural stem cells can be isolated from either embryonic or adult brains, and have the capacity to proliferate from single cells in response to growth factors such as epidermal growth factor (Reynolds and Weiss, 1996; Vescovi et al, 1999). In brain stem cell culture, neurospheres formed by neural stem/progenitor cells also showed susceptibility to MCMV infection (Kosugi et al, 2000).

In CMV infection, susceptibility to viral infection at the cellular level seems to be associated with transcriptional regulation rather than with viral receptors. The receptor for CMV has not been identified, although a few candidates have been reported (Nowlin et al, 1991). The IE gene promoter of MCMV, the activation of which is dependent on cellular transcription factors that bind to the DNA sequence of the enhancer/promoter (Griffiths and Grundy, 1987; Mocarski, 1996), was transferred into brain slice cultures using a gene gun. Activation of the promoter was observed mainly in immature glial cells, including neural progenitor cells, of the SVZ, as detected by immunostaining (data not shown). The number of cells in which the IE promoter was activated decreased with the brain development, whereas the number of cells able to activate the promoter transferred by gene gun was increased by culturing a slice for a longer preinoculation period. It is possible that the proliferation of cells with the potential to activate this promoter was associated with the stimulation of the differentiation of the susceptible cells from the stem/progenitor cells in the SVZ during preinoculation period. This suggests that the susceptibility of neural cells to MCMV infection may be regulated at the level of transcription of the IE gene. In this connection, we reported that the IE promoter was activated in glial progenitor cells in the SVZ during the brain development in transgenic mice (Aiba-Masago et al, 1999; Li et al, 2001).

The results of the present study suggest that immature glial cells, including neural progenitor cells, in the SVZ may also be an important factor in immunocompromised patients, especially those suffering from AIDS. Neurogenesis and gliogenesis continue throughout life, and multipotential neural stem cell can be isolated from the adult brain (Doetsch et al, 1999; Gage, 2000; Gage et al, 1995; Johansson et al, 1999; McKay, 1997; Morshead et al, 1994). It was reported that cells of the ventricular wall are susceptible to CMV infection in adult AIDS patients (Morgello et al, 1987; Setinek et al, 1995; Wiley and Nelson, 1988). Substantial neuronal cell loss was reported in the autopsied brains of AIDS patients (Everall et al, 1993; Petito et al, 1999). It is possible that this neuronal cell loss may induce neuronal regeneration in the SVZ (Biebl et al, 2000; Magavi et al, 2000). Recently, Jin et al (2001) reported that neurogenesis in the SVZ was induced after focal ischemia in the rat. In the brain slice culture system, it was reported that a significant amount of neuronal cell death also occurred during culture (Morrison et al, 2000; Okada et al, 1995), resulting in stimulation of neurogenesis (Biebl et al, 2000). These findings suggest that CMV-susceptible immature glial cells, including neural progenitor cells, may proliferate in damaged brains with neural regeneration, such as the brains of AIDS patients.

In summary, immature glial cells, including neural progenitor cells, in the SVZ and marginal area were the cells most susceptible to MCMV infection in brain slice cultures from neonatal mice, and the susceptibility declined as the number of immature glial cells decreased with age. The immature glial cells proliferated in brain slice cultures during prolonged incubation, and the susceptibility to MCMV infection increased in association with the proliferation of these cells. These results suggest that the number of the immature glial cells may be closely associated with the susceptibility of the brain to CMV infection.

\section{Materials and Methods}

\section{Organotypic Brain Slice Culture}

BALB/C and C57BL/6 mice were purchased from Japan Slc Co. (Hamamatsu, Japan). The cerebral slice culture was performed basically according to the method of Stoppini et al (1991) with some modifications (Shinmura et al, 1999). Brain slices were prepared from 0-, 7-, 14-, and 21-day-old mice. The whole brains, dissected from each mouse and kept in cold HBSS (Gibco BRL, Grand Island, New York) on ice, were fixed on a stage with instant glue and cut coronally at $400-\mu \mathrm{m}$ thickness with a microslicer (Dohan EM, Kyoto, Japan). Slices were transferred to porous transparent membranes (Millicell-CM, $0.4 \mathrm{~mm}$; Millipore, Bedford, Massachusetts) that were floated on culture medium in six-well plate (Becton Dickinson, Franklin Lakes, New Jersey), as reported previously (Shinmura et al, 1999). The culture medium was made according to Holmes et al (1995) with modifications. The medium consisted of $50 \%$ MEM (Gibco BRL), $25 \%$ HBSS, 25\% heat-inactivated horse serum (Gibco $\mathrm{BRL}$ ), supplemented with $6.5 \mathrm{mg} / \mathrm{ml}$ glucose, 0.15 $\mathrm{mg} / \mathrm{ml}$ glutamine, $30 \mathrm{~mm} \mathrm{NaHCO}, 100 \mathrm{U} / \mathrm{ml}$ penicillin, and $50 \mu \mathrm{g} / \mathrm{ml}$ streptomycin. The serum-free medium was prepared according to the method of Brewer et al (1993) with the modification of Czapiga and Colton (1999). The medium consisted of neurobasal-A medium (Gibco BRL) supplemented with B27 (Gibco $\mathrm{BRL}), 0.15 \mathrm{mg} / \mathrm{ml}$ glutamine, $100 \mathrm{U} / \mathrm{ml}$ penicillin, and $50 \mu \mathrm{g} / \mathrm{ml}$ streptomycin. The slices were maintained at $37^{\circ} \mathrm{C}$ in a humidified incubator with 95\% air and 5\% $\mathrm{CO}_{2}$. For labeling with 5-bromo-2-deoxyuridine (BrdU), brain slices were cultured continuously for 14 days in the presence of $1 \mu \mathrm{M} \mathrm{BrdU}$ in the culture medium.

\section{Preparation of Virus}

Recombinant MCMV (RM461) was used in the present study because the infected cells can be detected macroscopically in the brain slices by histochemical staining of $\beta$-Gal expression. The RM461 virus, in which the Escherichia coli lacZ gene was inserted into 
the $\gamma-0.85$ gene so that $\beta$-Gal was expressed under the control of the human CMV IE promoter, was provided by Dr. E. S. Mocarski (Stanford University, Stanford, California) (Stoddart et al, 1994).

\section{Virus Infection of Brain Slices}

Virus infection of the cerebral slices was performed as follows. Brain slices on membranes were covered with recombinant virus $\left(5 \times 10^{6} \mathrm{PFU} / \mathrm{ml}\right)$ over their whole surfaces and incubated for 1 hour with occasional shaking, washed two times with HBSS, and cultured in the slice culture medium as described above. As another infection method, virus was injected into brain slices by using microcapillary pipettes as described previously (Shinmura et al, 1999). Slices on the cell culture membranes were infected by injecting a viral solution $\left(5 \times 10^{6} \mathrm{PFU} / \mathrm{ml}\right)$ and fast green $(0.3 \%$ final concentration) into the extracellular space of brain slices using a micromanipulator (Narishige, Tokyo, Japan) under a stereoscopic microscope (Olympus, Tokyo, Japan). In all experiments, three brain slices were used for each experimental point. At least three independent experiments were performed.

\section{X-Gal Staining}

After incubation for appropriate times, the slices on membranes were fixed in $4 \%$ paraformaldehyde (PFA) for 20 minutes and washed with PBS at $4^{\circ} \mathrm{C}$. The staining of the virus-infected slices for $\beta$-Gal activity, which indicates the expression of the viral late gene, was performed by the method described by Reynolds et al (1994) using the substrate 5-bromo-4-chloro-3indolyl- $\beta$-galactoside (X-Gal).

\section{Quantitative Analysis of Virus-Infected Area and Neural Marker-Expressing Cells in Brain Slices}

The ratio of the $\mathrm{X}$-gal-positive area to the whole-brain slice area was calculated using Adobe PhotoShop v. 5.5 (Adobe Systems, Mountain View, California). Photos were taken of each brain slice stained with X-Gal and converted into digital information. Whole brain slice and X-Gal-stained areas were converted into pixel counts. The infection ratio was expressed by dividing the pixel count of the X-Gal-stained area by the pixel count of the whole brain slice area. For quantification of neural marker-expressing cells, immunostaining cells were counted in whole-brain sections by counting spherical nuclei in the immunostained area. Data were expressed as total cell counts per section. The counting was performed in at least three serial sections.

\section{Immunohistochemistry}

After fixation and $\mathrm{X}$-Gal staining, brain slices were embedded in paraffin and serially sectioned $(5 \mu \mathrm{m}$ thick). After treatment with hydrogen peroxidase, sections were incubated with rabbit serum or goat serum for 10 minutes at room temperature. The immunohistochemical staining was performed using a rabbit anti-glial fibrillary acidic protein antiserum (GFAP; Dako, Carpinteria, California) for astrocytes, a rabbit anti-nestin antiserum (Dr. H. Kitani, National Institute of Animal Health, Tsukuba, Japan) (Tomooka et al, 1993) for undifferentiated neural precursor cells (Lendahl et al, 1990), rat monoclonal antibody (mAb) specific to mouse Musashi- 1 for CNS progenitor cells, including neural stem cells (Kaneko et al, 2000), mouse mAb anti-MAP2 (microtubule-associated protein 2a and 2b; Sigma, St Louis, Missouri) for neurons, or a rabbit polyclonal anti-von Willebrand factor antibody for vascular endothelium (Dako), followed by incubation with biotinylated secondary antibody and HRP-conjugated streptavidin, and coloring with 3,3'diaminobenzidine- $4 \mathrm{HCl}$ (brown). The visualization of $\mathrm{BrdU}$ in the histologic sections in the cultured slices was performed according to the method of Roberts et al (1993) and was also described previously (Shinmura et al, 1997b). Sections were treated with pepsin, denatured with $2 \mathrm{~N} \mathrm{HCl}$, incubated with goat serum for blocking nonspecific reactions, incubated with antiBrdU mouse monoclonal antibody (Dako), and sequentially incubated with biotinylated goat anti-mouse IgG antibody and alkaline-phosphatase-conjugated streptavidin, and colored with fast red BB salt (Sigma) in the presence of naphthol AS-MX phosphate (Sigma).

For immunohistochemical double staining, sections were first reacted with the $\mathrm{N} 2 \mathrm{mAb}$ to the MCMV IE antigen-1 (Shinmura et al, 1997a), then sequentially incubated with biotinylated anti-rat IgG antibody and alkaline-phosphatase-conjugated streptavidin and colored with fast blue BB salt (Sigma) in the presence of naphthol AS-MX phosphate (Sigma). Next, the sections were reacted with the neural marker antibodies as described above, followed by incubation with biotinylated secondary antibody and HRP-conjugated streptavidin, and coloring with 3,3'-diaminobenzidine$4 \mathrm{HCl}$ (brown).

\section{Preparation of MCMV Immediate-Early Gene Promoter-lacZ Gene Construct}

In CMV infection, the IE genes are expressed first, and regulate the subsequent expression of the early and late genes. The expression of the IE genes is dependent on appropriate cellular transcription factors (Mocarski, 1996). We constructed an MCMV IE gene promoter-lacZ reporter gene for expression analyses in vitro and in vivo (Aiba-Masago et al, 1999). The MCMV-IE promoter region containing nucleotides -1343 to -6 (1338 bp) was inserted into the pnlacF vector containing the nuclear localization signal from SV40, Escherichia coli $\beta$-galactosidase ( $\beta$-Gal) coding sequence, and a sequence for $\operatorname{poly}(\mathrm{A})$ and an intron from mouse protamine, provided by Dr. R. D. Palmiter, University of Washington (Mercer et al, 1991).

\section{Gene Transfer Into Brain Slices Using a Gene Gun}

The MCMV IE promoter-lacZ DNA construct was injected into brain slices using the gene gun of the 
PIGG-1 system (Nippon Ikakikai Seisakusho, Tokyo, Japan), in which DNA-coated gold particles were released on brain slices by a shock of helium onto the reverse side of the microcarriers. The gold particles (2.5 mg; Tokuriki Honten, Tokyo, Japan), $1 \mu \mathrm{m}$ in diameter, were washed and sonicated in $100 \%$ ethanol, and then collected by centrifugation and dried. Twenty microliters of the DNA $(0.5 \mu \mathrm{g} / \mu \mathrm{l}$ in TE) was added to the gold particles, and then the solution containing DNA on gold particles was mildly sonicated to cause attachment of the DNA to the metal. The DNA-coated gold particles were injected into brain slices in a vacuum-box using the gene gun with a pressure of $12 \mathrm{kgf} / \mathrm{cm}^{2}$. X-Gal staining was performed 48 hours after injection. The total numbers of transfected cells in brain slices of each stage were counted.

\section{Acknowledgements}

We thank Dr. E. S. Mocarski, Department of Microbiology and Immunology, Stanford University School of Medicine, for providing the recombinant MCMV (RM461). We also thank Dr. S. Sakakibara and Dr. H. Okano, Department of Physiology, Keio University School of Medicine, for providing the monoclonal antibody to Musashi-1.

\section{References}

Aiba-Masago S, Baba S, Li RY, Shinmura Y, Kosugi I, Arai Y, Nishimura M, and Tsutsui $Y$ (1999). Murine cytomegalovirus immediate-early promoter directs astrocyte-specific expression in transgenic mice. Am J Pathol 154:735-743.

Alvarez-Buylla A, Garcia-Verdugo JM, and Tramontin AD (2001). A unified hypothesis on the lineage of neural stem cells. Nat Rev Neurosci 2:287-293.

Bale JF (1984). Human cytomegalovirus infection and disorders of the nervous system. Arch Neurol 41:310-320.

Barres BA (1999). A new role for glia: Generation of neurons. Cell 97:667-670.

Becroft DMO (1981). Prenatal cytomegalovirus infection: Epidemilolgy, pathology, pathogenesis. In: Rosenberg HS and Bernstein J, editors. Perspectives in pediatric pathology. New York: Massohn, 203-241.

Biebl M, Cooper CM, Winkler J, and Kuhn HG (2000). Analysis of neurogenesis and programmed cell death reveals a self-renewing capacity in the adult rat brain. Neurosci Lett 291:17-20.

Booss J, Dann PR, Griffith BP, and Kim JH (1989). Host defense response to cytomegalovirus in the central nervous system. Am J Pathol 134:71-78.

Brewer GJ, Torricelli JR, Evege EK, and Price PJ (1993). Optimized survival of hippocampal neurons in B27supplemented Neurobasal, a new serum-free medium combination. J Neurosci Res 35:567-576.

Britt WJ and Alford CA (1996). Cytomegalovirus. Virology, 3rd ed. Fields BN, Knipe DM, and Howley PM, editors. Philadelphia: Lippincott-Raven, 2493-2523.

Brutkiewicz RR and Welsh RM (1995). Major histocompatibility complex class I antigens and the control of viral infections by natural killer cells. J Virol 69:3967-3971.
Cinque P, Marenzi R, and Ceresa D (1997). Cytomegalovirus infections of the nervous system. Intervirology 40:85-97.

Coltman BW and Ide CF (1996). Temporal characterization of microglia, IL-1 beta-like immunoreactivity and astrocytes in the dentate gyrus of hippocampal organotypic slice cultures. Int J Dev Neurosci 14:707-719.

Colton CA, Yao J, Keri JE, and Gilbert D (1992). Regulation of microglial function by interferons. J Neuroimmunol 40:89-98.

Conboy TJ, Pass RF, Stagno S, Britt WJ, Alford CA, McFarland CE, and Boll TJ (1986). Intellectual development in school-aged children with asymptomatic congenital cytomegalovirus infection. Pediatrics 77:801-806.

Crino PB and Eberwine J (1997). Cellular and molecular basis of cerebral dysgenesis. J Neurosci Res 50:907-916.

Czapiga M and Colton CA (1999). Function of microglia in organotypic slice cultures. J Neurosci Res 56:644-651.

Demmler GJ (1991). Infectious Diseases Society of America and Centers for Disease Control. Summary of a workshop on surveillance for congenital cytomegalovirus disease. Rev Infect Dis 13:315-329.

Doetsch F, Caille I, Lim DA, Garcia-Verdugo JM, and AlvarezBuylla A (1999). Subventricular zone astrocytes are neural stem cells in the adult mammalian brain. Cell 97:703-716.

Everall I, Luthert P, and Lantos P (1993). A review of neuronal damage in human immunodeficiency virus infection: Its assessment, possible mechanism and relationship to dementia. J Neuropathol Exp Neurol 52:561-566.

Forbes CA, Brown MG, Cho R, Shellam GR, Yokoyama WM, and Scalzo AA (1997). The Cmv1 host resistance locus is closely linked to the Ly49 multigene family within the natural killer cell gene complex on mouse chromosome 6 . Genomics 41:406-413.

Gage FH (2000). Mammalian neural stem cells. Science 287:1433-1438.

Gage FH, Ray J, and Fisher LJ (1995). Isolation, characterization, and use of stem cells from the CNS. Annu Rev Neurosci 18:159-192.

Ghazal P and Nelson JA (1993). Transcription factors and viral regulatory proteins as potential mediators of human cytomegalovirus pathogenesis. In: Becker Y, Darai G, and Huang E-S, editors. Molecular aspects of human cytomegalovirus diseases. Berlin: Springer-Verlag, 360-383.

Griffiths PD and Grundy JE (1987). Molecular biology and immunology of cytomegalovirus. Biochem J 241:313-324.

Hayashi K, Eizuru Y, Sato S, and Minamishima Y (1985). The role of NK cell activity in age-dependent resistance of mice to murine cytomegalovirus infection. Microbiol Immunol 29: 939-950.

Haydar TF, Wang F, Schwartz ML, and Rakic P (2000). Differential modulation of proliferation in the neocortical ventricular and subventricular zones. J Neurosci 20:57645774.

Ho M (1991). Congenital and perinatal human cytomegalovirus infection. In: Ho M, editor. Cytomegalovirus: Biology and infection. New York: Plenum Press, 205-277.

Holmes C, Jones SA, and Greenfield SA (1995). The influence of target and non-target brain regions on the development of mid-brain dopaminergic neurons in organotypic slice culture. Brain Res Dev Brain Res 88:212-219. 
Jin K, Minami M, Lan JQ, Mao XO, Batteur S, Simon RP, and Greenberg DA (2001). Neurogenesis in dentate subgranular zone and rostral subventricular zone after focal cerebral ischemia in the rat. Proc Natl Acad Sci USA 98:4710-4715.

Johansson CB, Momma S, Clarke DL, Risling M, Lendahl U, and Frisen J (1999). Identification of a neural stem cell in the adult mammalian central nervous system. Cell 96:25-34.

Kaneko Y, Sakakibara S, Imai T, Suzuki A, Nakamura Y, Sawamoto K, Ogawa Y, Toyama Y, Miyata T, and Okano H (2000). Musashi1: An evolutionally conserved marker for CNS progenitor cells including neural stem cells. Dev Neurosci 22:139-153.

Kosugi I, Shinmura Y, Kawasaki H, Arai Y, Li RY, Baba S, and Tsutsui $Y$ (2000). Cytomegalovirus infection of the central nervous system stem cells from mouse embryo: A model for developmental brain disorders induced by cytomegalovirus. Lab Invest 80:1373-1383.

Lendahl U, Zimmerman LB, and McKay RD (1990). CNS stem cells express a new class of intermediate filament protein. Cell 60:585-595.

Li RY, Baba S, Kosugi I, Arai Y, Kawasaki H, Shinmura Y, Sakakibara S, Okano H, and Tsutsui $Y$ (2001). Activation of murine cytomegalovirus immediate-early promoter in cerebral ventricular zone and glial progenitor cells in transgenic mice. Glia 35:41-52.

Li RY and Tsutsui Y (2000). Growth retardation and microcephaly induced in mice by placental infection with murine cytomegalovirus. Teratology 62:79-85.

Lo DC, McAllister AK, and Katz LC (1994). Neuronal transfection in brain slices using particle-mediated gene transfer. Neuron 13:1263-1268.

Magavi SS, Leavitt BR, and Macklis JD (2000). Induction of neurogenesis in the neocortex of adult mice. Nature 405: 951-955.

McKay R (1997). Stem cells in the central nervous system. Science 276:66-71.

Mercer EH, Hoyle GW, Kapur RP, Brinster RL, and Palmiter $\mathrm{RD}$ (1991). The dopamine beta-hydroxylase gene promoter directs expression of $\mathrm{E}$. coli lacZ to sympathetic and other neurons in adult transgenic mice. Neuron 7:703-716.

Mocarski ES Jr (1996) Cytomegalovirus and their replication. In: Field BN, Knipe DM, and Howley PM, editors. Virology, 3rd ed. Philadelphia: Lippincott-Raven, 2447-2449.

Morgello S, Cho ES, Nielsen S, Devinsky O, and Petito CK (1987). Cytomegalovirus encephalitis in patients with acquired immnunodeficiency syndrome: An autopsy study of 30 cases and a review of literature. Hum Pathol 18:289-297.

Morrison B III, Eberwine JH, Meaney DF, and Mclntosh TK (2000). Traumatic injury induces differential expression of cell death genes in organotypic brain slice cultures determined by complementary DNA array hybridization. Neuroscience 96:131-139.

Morshead CM, Reynolds BA, Craig CG, McBurney MW, Staines WA, Morassutti D, Weiss S, and van der Kooy D (1994). Neural stem cells in the adult mammalian forebrain: A relatively quiescent subpopulation of subependymal cells. Neuron 13:1071-1082.

Nelson JA, Gnann JW Jr, and Ghazal P (1990). Regulation and tissue-specific expression of human cytomegalovirus. Curr Top Microbiol Immunol 154:75-100.
Nowlin DM, Cooper NR, and Compton T (1991). Expression of a human cytomegalovirus receptor correlate with infectivity of cells. J Virol 65:3114-3121.

Okada M, Sakaguchi T, and Kawasaki K (1995). Correlation between anti-ubiquitin immunoreactivity and region-specific neuronal death in $\mathrm{N}$-methyl-D-aspartate-treated rat hippocampal organotypic cultures. Neurosci Res 22:359-366.

Pass RF, Stagno S, Myers GJ, and Alford CA (1980). Outcome of symptomatic congenital cytomegalovirus infection: Results of long-term longitudinal follow-up. Pediatrics 66: 758-762.

Perlman JM and Argyle C (1992). Lethal cytomegalovirus infection in preterm infants: Clinical, radiological, and neuropathological findings. Ann Neurol 31:64-68.

Petito CK, Kerza-Kwiatecki AP, Gendelman HE, McCarthy M, Nath A, Podack ER, Nath A, Podack ER, Shapshak P, and Wiley CA (1999). Review: Neuronal injury in HIV infection. J Neurovirol 5:327-341.

Reynolds BA and Weiss S (1996). Clonal and population analyses demonstrate that an EGF-responsive mammalian embryonic CNS precursor is a stem cell. Dev Biol 175:1-13.

Reynolds K, Mezey E, and Zimmer A (1994). Activity of the beta-retinoic acid receptor promoter in transgenic mice. Mech Dev 36:15-29.

Roberts JS, O'Rourke NA, and McConnell SK (1993). Cell migration in cultured cerebral cortical slices. Dev Biol 155: 396-408.

Sakakibara S, Imai T, Hamaguchi K, Okabe M, Aruga J, Nakajima K, Yasutomi D, Nagata T, Kurihara Y, Uesugi S, Miyata T, Ogawa M, Mikoshiba K, and Okano H (1996). Mouse-Musashi-1, a neural RNA-binding protein highly enriched in the mammalian CNS stem cell. Dev Biol 176:230242.

Scalzo AA, Fitzgerald NA, Simmons A, La Vista AB, and Shellam GR (1990). Cmv-1, a genetic locus that controls murine cytomegalovirus replication in the spleen. J Exp Med 171:1469-1483.

Scalzo AA, Fitzgerald NA, Wallace CR, Gibbons AE, Smart YC, Burton RC, and Shellam GR (1992). The effect of the Cmv-1 resistance gene, which is linked to the natural killer cell gene complex, is mediated by natural killer cells. J Immunol 149:581-589.

Setinek U, Wondrucsh E, Jellinger K, Steuer A, Drlicek M, Grisold W, and Lintner F (1995). Cytomegalovirus infection of the brain in AIDS: A clinicopathological study. Acta Neuropathol 90:511-515.

Shinmura Y, Aiba-Masago S, Kosugi I, Li RY, Baba S, and Tsutsui Y (1997a). Differential expression of the immediateearly and early antigens in neuronal and glia cells of developing mouse brains infected with murine cytomegalovirus. Am J Pathol 151:1331-1340.

Shinmura Y, Kosugi I, Aiba-Masago S, Baba S, Li RY, and Tsutsui $Y$ (1997b). Disordered migration and loss of viralinfected neuronal cells in developing mouse brains infected with murine cytomegalovirus. Acta Neuropathol 93:551-557.

Shinmura Y, Kosugi I, Kaneta M, and Tsutsui Y (1999). Migration of virus-infected neuronal cells in cerebral slice cultures of developing mouse brains after in vitro infection with murine cytomegalovirus. Acta Neuropathol 98:590-596. 
Sinzger C, Grefte A, Plachter B, Gouw AS, The TH, and Jahn G (1995). Fibroblasts, epithelial cells, endothelial cells and smooth muscle cells are major targets of human cytomegalovirus infection in lung and gastrointestinal tissues. J Gen Virol 76:741-750.

Söderberg-Nauclér C and Nelson JY (1999). Human cytomegalovirus latency and reactivation-a delicate balance between the virus and its host's immune system. Intervirology 42:314-321.

Stagno S, Pass RF, Cloud G, Britt WJ, Henderson RE, Walton PD, Veren DA, Page F, and Alford CA (1986). Primary cytomegalovirus infection in pregnancy. Incidence, transmission to fetus, and clinical outcome. JAMA 256:1904-1908.

Stoddart CA, Cardin RD, Boname JM, Manning WC, Abenes GB, and Mocarski ES (1994). Peripheral blood mononulcear phagocytes mediate dissemination of murine cytomegalovirus. J Virol 68:6243-6253.

Stoppini L, Buchs P-A, and Muller D (1991). A simple method for organotypic cultures of nervous tissue. J Neurosci Methods 37:173-182.

Tomooka Y, Kitani H, Jing N, Matsushima M, and Sakakura T (1993). Reconstruction of neural tube-like structures in vitro from primary neural precursor cells. Proc Natl Acad Sci USA 90:9683-9687.

Tsutsui $Y$ (1995). Developmental disorders of the mouse brain induced by murine cytomegalovirus: Animal models for congenital cytomegalovirus infection. Pathol Int 45:91-102.

Tsutsui Y, Kashiwai A, Kawamura N, Aiba-Masago S, and Kosugi I (1995). Prolonged infection of mouse brain neurons with murine cytomegalovirus after pre- and perinatal infection. Arch Virol 140:1725-1736.
Tsutsui Y, Kashiwai A, Kawamura N, and Kadota C (1993). Microphthalmia and cerebral atrophy induced in mouse embryos by infection with murine cytomegalovirus in midgestation. Am J Pathol 143:804-813.

van den Pol AN, Mocarski E, Saederup N, Vieira J, and Meier TJ (1999). Cytomegalovirus cell tropism, replication, and gene transfer in brain. J Neurosci 19:10948-10965.

van den Pol AN, Vieira J, Spencer DD, and Santarelli JG (2000). Mouse cytomegalovirus in developing brain tissue: Analysis of 11 species with GFP-expressing recombinant virus. J Comp Neurol 427:559-580.

Vescovi AL, Parati EA, Gritti A, Poulin P, Ferrario M, Wanke E, Frolichsthal-Schoeller P, Cova L, Arcellana-Panlilio M, Colombo A, and Galli R (1999). Isolation and cloning of multipotential stem cells from the embryonic human CNS and establishment of transplantable human neural stem cell lines by epigenetic stimulation. Exp Neurol 156:71-83.

Weller TH (1971). The cytomegalovirus: Ubiquitous agents with protean clinical manifestations. N Eng J Med 285:203214.

Wiley CA and Nelson JA (1988). Role of human immnodeficency virus and cytomegalovirus in AIDS encephalitis. Am J Pathol 133:73-81. 